\title{
ВМІСТ КИСЛОТ ГІДРОКСИКОРИЧНИХ У ТРАВІ ТА КОРЕНЕВИЩАХ I КОРЕНЯХ БЕДРИНЦЮ ЛОМИКАМЕНЕВОГО (PIMPINELLA SAXIFRAGA L.)
}

Вступ. Бедринець ломикаменевий (Pimpinella saxifraga L.) з родини селерові (Apiaceae) здавна у народній медицині застосовують як відхаркувальний, сечогінний, протизапальний, седативний, болетамувальний засіб. Його рекомендують при катарі дихальних иляхів, трахеїті, бронхіті, пневмонії, ларингіті, астмі, коклюші, водянці, сольових діатезах, захворюваннях печінки, атонії кишечника, хронічному гастриті зі зниженою кислотністю, подагрі, набряках та метеоризмі. 3 лікувальною метою використовують в основному кореневища і корені рослини. Відомо близько 200 видів роду Бедринець (Pimpinella L.), поширених в Азії, Європі й Афрриці. В Україні зустрічаються 5 видів; найпоширенішим є бедринець ломикаменевий.

Мета дослідження - встановити наявність і визначити кількісний вміст кислот гідроксикоричних у траві та підземних органах бедринцю ломикаменевого.

Методи дослідження. Для виявлення кислот гідроксикоричних використовували спиртово-водну витяжку. Реакція з 1 \% розчином фрерум (III) хлориду (поява зелено-сірого забарвлення) свідчила про наявність у досліджуваній витяжці сполук френольної природи. Кількісне визначення кислот гідроксикоричних у досліджуваних об'єктах грунтується на спектрофотометричному методі. Якісний склад і кількісний вміст індивідуальних кислот гідроксикоричних у траві та підземних органах бедринцю ломикаменевого досліджували методом високоефективної рідинної хроматографрії на хроматографрі Agilent 12003 D LC System Technologies (США).

Результати й обговорення. Кількісний вміст суми кислот гідроксикоричних у траві бедринцю ломикаменевого становив $(4,68 \pm 0,05) \%$, в підземних органах - $(1,52 \pm 0,03) \%$. Методом високоефективноі рідинної хроматографрії в досліджуваних об'єктах рослини виявлено й ідентифріковано кислоти хлорогенову і розмаринову та встановлено їх кількісний вміст. У траві й підземних органах бедринцю ломикаменевого в основному домінує кислота хлорогенова, вміст якої становив 3,13 і 0,11 \% відповідно. У траві рослини міститься 0,34 \% кислоти розмаринової.

Висновки. Встановлено наявність і визначено кількісний вміст кислот гідроксикоричних у траві та підземних органах бедринцю ломикаменевого, який становив $(4,68 \pm 0,05)$ i $(1,52 \pm 0,03)$ \% відповідно. Методом високоефективної рідинної хроматографії в досліджуваній сировині рослини виявлено індивідуальні кислоти гідроксикоричні - хлорогенову і розмаринову, визначено їх кількісний вміст. У траві й підземних органах бедринцю ломикаменевого домінує кислота хлорогенова, вміст якої становив 3,13 і 0,34 \% відповідно, тому їі можна рекомендувати для стандартизації сировини.

КЛЮЧОВІ СЛОВА: бедринець ломикаменевий; кислоти гідроксикоричні; кислота хлорогенова; спектрофотометричний метод; високоефективна рідинна хроматографія.

ВСТУП. Бедринець ломикаменевий (Pimpinella saxifraga L.) з родини селерові (Apiaceae) здавна у народній медицині застосовують як відхаркувальний, сечогінний, протизапальний, седативний, болетамувальний засіб. Його рекомендують при катарі дихальних шляхів, трахеїті, бронхіті, пневмонії, ларингіті, астмі, коклюші, водянці, сольових діатезах, захворюваннях печінки, атонії кишечника, хронічному гастриті зі зниженою кислотністю, подагрі, набряках та метеоризмі [1].

(с) Е. А. Паращук, С. М. Марчишин, М. В. Кирилів, І. Р. Бекус, 2018.
3 лікувальною метою використовують в основному кореневища і корені рослини. Відомо близько 200 видів роду Бедринець (Pimpinella L.), поширених в Азії, Європі й Асрриці. В Україні зустрічаються 5 видів: бедринець великий (Pimpinella major (L.) Huds.), бедринець іноземний (Pimpinella peregrina L.), бедринець каменелюбний (Pimpinella lithophila Schischkin), бедринець вапнолюбний (Pimpinella titanophila Woronow), бедринець ломикаменевий (Pimpinella saxifraga L.) [2]. Найпоширенішим $є$ бедринець ломикаменевий, який зростає по всій Україні на сухих луках, у соснових лісах, на кам'янистих 
вапнякових схилах, серед чагарників і на полянах.

Попередні дослідження показали, що бедринець ломикаменевий містить органічні й жирні кислоти, фрлавоноїди, дубильні речовини, амінокислоти, вуглеводи [3, 4].

Мета дослідження - встановити наявність і визначити кількісний вміст кислот гідроксикоричних у траві та кореневищах і коренях бедринцю ломикаменевого, які заготовляли на трав'янистих пагорбах та схилах у Гусятинському районі Тернопільської області у 2016 р. Траву заготовляли в липні - серпні, підземні органи - восени після відмирання надземної частини рослини.

МЕТОДИ ДОСЛІДЖЕННЯ. Для вияВлення кислот гідроксикоричних використовували спиртово-водну витяжку. Реакція $31 \%$ розчином фрерум (III) хлориду (поява зелено-сірого забарвлення) свідчила про наявність у досліджуваній витяжці сполук френольної природи.

Кількісне визначення гідроксикоричних кислот у досліджуваних об'єктах ґрунтується на спектрофротометричному методі [5-7].

2,0 г (точна наважка) подрібненої сировини поміщали в колбу місткістю 200 мл і заливали 70 мл 20 \% етанолу Р. Колбу приєднували до зворотного холодильника і нагрівали на водяній бані протягом 15 хв. Екстракцію проводили тричі. Екстракт охолоджували і фрільтрували крізь паперовий фрільтр, використовуючи лійку Бюхнера. Витяжку кількісно переносили в мірну колбу місткістю 250 мл і доводили об'єм розчину до мітки 20 \% етанолом Р (розчин А). У мірну колбу місткістю 50 мл вносили 1 мл розчину А доводили до мітки 20 \% етанолом Р. Оптичну густину розчину вимірювали на спектрофотометpi Lambda 25 за довжини хвилі 327 нм у кюветі 3 товщиною шару 10 мм. Для порівняння використовували $20 \%$ етанол Р.

Вміст кислот гідроксикоричних у перерахунку на абсолютно суху сировину у відсотках (X) обчислювали за фрормулою:

$$
X=\frac{A \cdot 250 \cdot 50 \cdot 100}{E_{1}^{1 \%} \cdot m \cdot 1 \cdot(100-W)},
$$

де A - оптична густина досліджуваного розчину;

250 - об'єм розчину, мл;

m - маса сировини, г;

$\mathrm{E}_{1 \mathrm{~cm}}^{1 \%}$ - питомий показник поглинання кислоти хлорогенової (531);

W - втрата в масі при висушуванні, \% [1].

Якісний склад та кількісний вміст кислот гідроксикоричних досліджували також методом високоефективної рідинної хроматографрії (BEPX). Хроматографрічне розділення здійсню- вали на рідинному хроматографрі Agilent 1200 3 D LC System Technologies (США) 3 діодноматричним детектором G1315C, на колонці Supelco Discovery C18 HPLC column 5 мкм при температурі термостата колонок $25^{\circ} \mathrm{C}$. Пробу вводили автосамплером (обсяг проби - 10 мкл, швидкість потоку - 0,7 мл/хв, робочий тиск елюенту 10 000-12 000 кПа).

Для приготування рухомої фрази використовували ацетонітрил марки Chromasolv gradient grade, for HPLC, >99,9 \% (Sigma-Aldrich), кислоту ортофоосоратну - Chromasolv gradient grade, for HPLC, >99,9 \% (Sigma-Aldrich), бідистильовану воду отримували на Simplicity SIMSV00 Water Purification System Millipore (Merck KGaA, Darmstadt, Germany). Для екстракції кислот гідроксикоричних застосовували метанол марки Chromasolv gradient grade, for HPLC, >99,9\% (Sigma-Aldrich). Стандартні речовини - кислоти хлорогенова, кофрейна, n-кумарова, ферулова, розмаринова - виробництва Sigma Chemical Co.

Підготовка проб для аналізу: близько 1 г рослинної сировини (точна наважка) екстрагували 50 мл $60 \%$ розчину метанолу протягом 15 хв на водяній бані зі зворотним холодильником при перемішуванні. Після цього фрільтрували, кількісно переносили в мірну колбу місткістю 100 мл і доводили об'єм розчину до мітки $60 \%$ метанолом. Отриманий розчин відфрільтровували крізь мембранний фрільтр із розміром пор 0,45 мкм.

Для поділу фенольних сполук застосовували такі умови: градієнтне елюювання сумішшю бідистильованої води, підкисленої кислотою ортофросфратною до $\mathrm{pH}=2,85$ (A), та ацетонітрилу (B): 0 хв $5 \%$ "В", 8 хв $8 \%$ "В", 15 хв $10 \%$ "В", 30 хв $20 \%$ "В", 40 хв $40 \%$ "В”, 41-42 хв $75 \%$ "В", 43-50 хв 5 \% при довжині детектування 320 і 330 Hм [8].

РЕЗУЛЬТАТИ Й ОБГОВОРЕННЯ. КіЛЬКіСНИЙ вміст суми кислот гідроксикоричних у перерахунку на абсолютно суху сировину становив у траві $(4,68 \pm 0,05) \%$, у кореневищах і коренях $(1,52 \pm 0,03) \%$.

Методом ВEРХ у траві бедринцю ломикаменевого було виявлено й ідентифіковано кислоти хлорогенову і розмаринову та встановлено їх кількісний вміст, у підземних органах - хлорогенову. Результати експерименту наведено на рисунках 1 і 2 й у таблиці.

Методом BEPX у досліджуваних об'єктах рослини виявлено й ідентифіковано кислоти хлорогенову і розмаринову та встановлено їх кількісний вміст. У траві та підземних органах бедринцю ломикаменевого в основному домінує кислота хлорогенова, вміст якої становив 3,13 і 


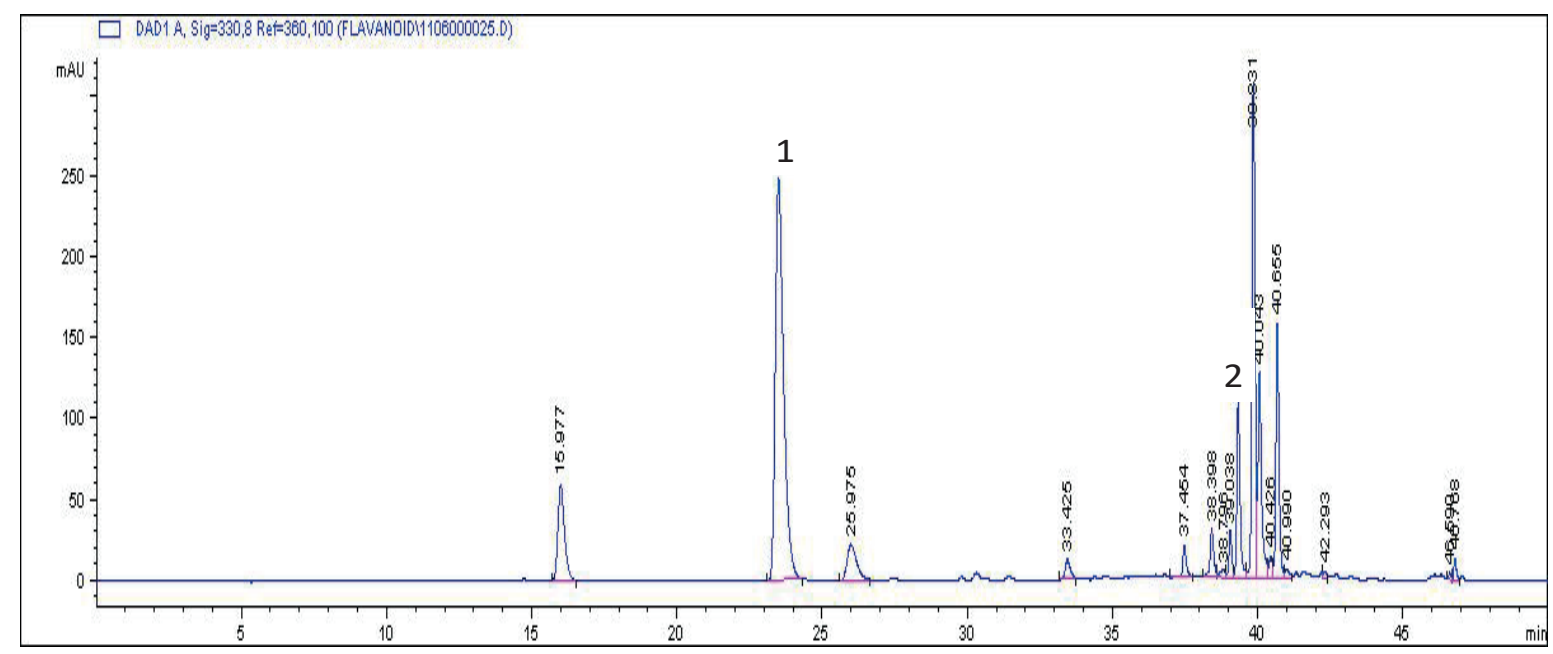

Рис. 1. BEPX-хроматограма водно-спиртової витяжки трави бедринцю ломикаменевого при $\lambda=330$ нм: 1 - кислота хлорогенова; 2 - кислота розмаринова.

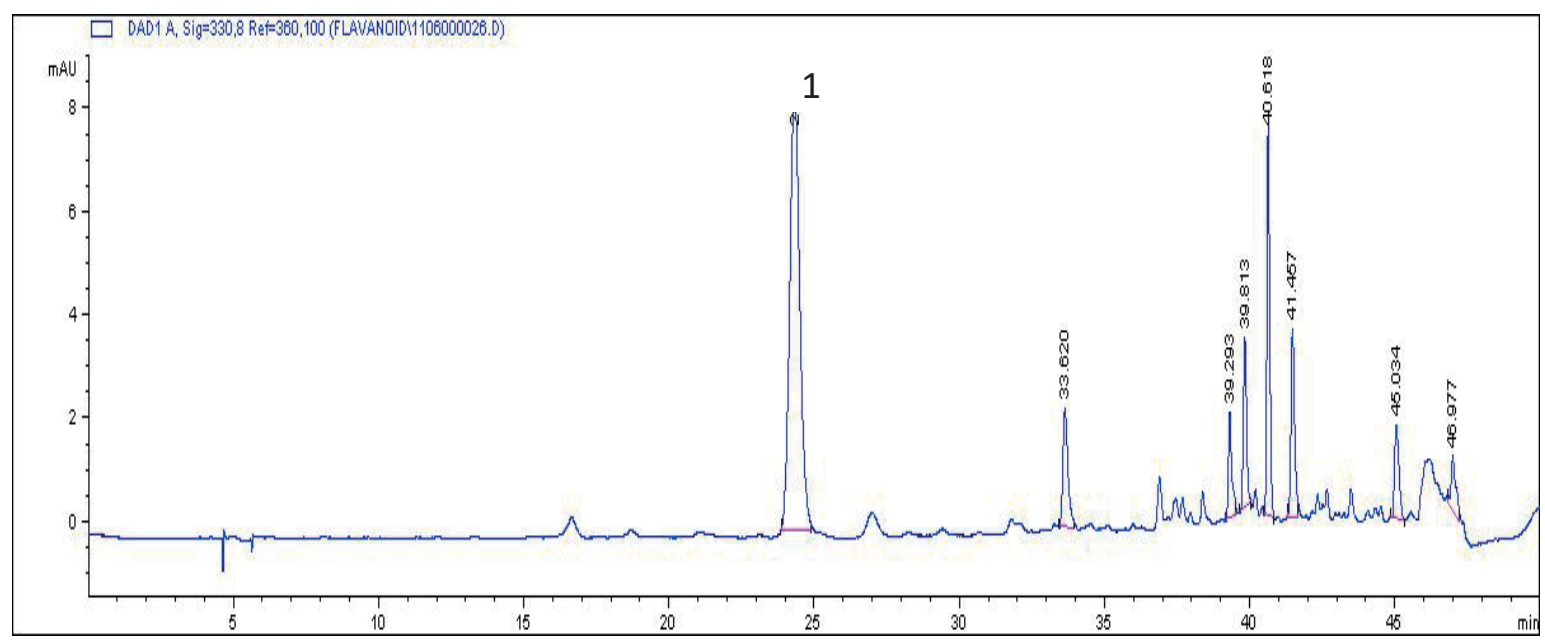

Рис. 2. BEPX-хроматограма водно-спиртової витяжки підземних органів бедринцю ломикаменевого при $\lambda=330$ нм: 1 - кислота хлорогенова.

Таблиця - Кількісний вміст кислот гідроксикоричних у сировині бедринцю ломикаменевого (високоефективна рідинна хроматографрія)

\begin{tabular}{|c|c|c|c|c|}
\hline \multirow{2}{*}{ БАР } & \multirow{2}{*}{$\begin{array}{l}\text { УФ-спектр } \\
\lambda \text { max, нм }\end{array}$} & \multirow{2}{*}{$\mathrm{RT}, \mathrm{xB}$} & \multicolumn{2}{|c|}{ Кількісний вміст, \% } \\
\hline & & & трава & кореневища і корені \\
\hline Кислота хлорогенова & 330 & $\begin{array}{l}23,479 \\
24,306 \\
\end{array}$ & 3,13 & 0,34 \\
\hline Кислота розмаринова & 330 & 39,309 & 0,11 & $\mathrm{H} / \mathrm{B}$ \\
\hline
\end{tabular}

Примітка. н/в - не визначено.

0,11 \% відповідно. У траві рослини міститься 0,34 \% кислоти розмаринової.

За даними літератури, кислота хлорогенова має жовчогінну, сечогінну, капілярозміцнювальну, протизапальну, антибактеріальну та антивірусну дію [9]. Вона є найпотужнішим фрункціональним інгібітором мікросомальних глюкозо-6-сроссрат транслоказ, які застосовують для хіміопрофрілактики онкологічних захворювань [10], а також перспективною сполукою для лікування ВІЛ-інфрікованих та хворих на СНІД [11, 12].
Кислоту хлорогенову широко застосовують у медичній практиці, побутовій хімії та харчовій промисловості [11].

ВИСНОВКИ. 1. Встановлено наявність і визначено кількісний вміст кислот гідроксикоричних у траві та підземних органах бедринцю ломикаменевого, який становив $(4,68 \pm 0,05) \mathrm{i}(1,52 \pm 0,03) \%$ відповідно.

2. Методом високоефективної рідинної хроматографіії в досліджуваній сировині рослини 
виявлено індивідуальні кислоти гідроксикоричні - хлорогенову і розмаринову, визначено їх кількісний вміст.
3. У траві й підземних органах бедринцю ломикаменевого домінує кислота хлорогенова, вміст якої становив 3,13 і 0,34 \% відповідно, тому ії̈ можна рекомендувати для стандартизації сировини.

7. Державна Фармакопея України / Держ. п-во "Український науковий фрармакопейний центр якості лікарських засобів". - 1-ше вид., доп. 3. - 2009. $280 \mathrm{c}$.

8. Марчишин С. М. Определение гидроксикоричных кислот в антиаллергическом сборе методом ВЭЖХ [Электронный ресурс] / С. М. Марчишин, С. С. Козачок // Сетевое научное издание : Медицина и образование Сибири. - 2013. - № 4. - Режим доступа : http://cyberleninka.ru/article/n/opredeleniegidroksikorichnyh-kislot-v-antiallergicheskom-sboremetodom-vezhh.

9. Jiang Y. Inhibition of chlorogenic acid induced cytotoxicity by CoC12 / Y. Jiang, K. Satoh, S. Watanabe // Anticancer Res. - 2001. - 21. - P. 3349-3353.

10. Pharmacodynamic profile of a novel inhibitor of the hepatic glucose-6-phosphatase system/ A. W. Herling, H. J. Burger, D. Schwab [et al.] // Amer. J. Physiol. 1998. - 274. - P. 1087-1093.

11. Войцехівська О. В. Фенольні сполуки: різноманіття, біологічна активність, перспективи застосування / О. В. Войцехівська, О. В. Ситар, Н. Ю. Таран // Вісн. Харк. нац. аграр. ун-ту. Серія "Біологія". -2015. Вип. 1 (34). - С. 104-119.

12. Ma B. Progress report on extraction and separation ofchlorogenic acid from eucomiaulmoides / B. Ma, S. Liang //Shanxi For. Sci. Technol. -2003. -4. -P. 74-79.

\section{REFERENCES}

1. Marchyshyn, S.M., \& Sushko, N.O. (2007). Likarski roslyny Ternopilshchyny [Medicinal plants of Ternopil region]. Ternopil: Navchalna knyha - Bohdan [in Ukrainian].

2. Dobrochayeva, D.N., Kotov, M.I., \& Prokudin, Yu.N. (1987). Opredelitel vysshykh rasteniy Ukrainy [The determinant of higher plants of Ukraine]. Kyiv: Naukova dumka [in Russian].

3. Marchyshyn, S.M., \& Panasiuk, E.A. (2016). Doslidzennia karbonovykh kyslot u nadzemnykh i pidzemnykh orhanakh bedryntsiu lomykamenevoho (Pimpinella saxifrage L.) [Investigation of carboxylic acids in the above-ground and underground organs of the femur (Pimpinella saxifrage L.)]. Farmatsiia XXI stolittia: tendentsii ta perspektyvy: materialy VIII Nats. Zizdu farmatsevtiv Ukrainy - Pharmacy of the 21st Century: Trends and Prospects: Materials of the VIII National University. the Congress of Pharmacists of Ukraine. September 1316. Kharkiv: NPhU. p. 112 [in Ukrainian].
4. Marchyshyn, S., Parashchuk, E., Dakhym, I., \& Husak, L. (2018). Phenolic compounds from Pimpinella saxifraga L. The Pharma Innovation Journal, 7 (6), 600602.

5. Marchyshyn, S., Hudz, N., Dakhym, I., Husak, L., \& Demydyak, O. (2018). HPLC analysis of phenolic compounds from Stevia rabaudiana Bertoni leaves. The Pharma Innovation Journal, 7 (3), 515-517.

6. Marchyshyn, S.M., Husak, L.V., \& Berdei, T.S. (2016). Doslidzhennia kyslot hidroksykorychnykh travy chystetsiu Zibolda [Investigation of acids of hydroxycoric grass purified by Zibold]. Med. i klin. Khimiia - Medical and Clinical Chemistry, 3, 13-16 [in Ukrainian].

7. (2009). Derzhavna Farmakopeia Ukrainy [State Pharmacopoeia of Ukraine]. State enterprise "Ukrainian Scientific Pharmacopoeial Center for the Quality of Medicinal Products" [in Ukrainian].

8. Marchyshyn, S.M., \& Kozachok, S.S. (2013). Opredeleniye gidroksikorichnykh kislot v antiallergishes- 
kom sbore metodom VEZHKh [Determination of hydroxycinnamic acids in antiallergic collection by HPLC]. Setevoe nauchn. izd: Meditsina i obrazovanie Sibiri Network Scientific Publishing House: Medicine and Education of Siberia, 4. Retrieved from: http://cyberleninka. ru/article/n/opredelenie-gidroksikorichnyh-kislot-vantiallergicheskom-sbore-metodom-vezhh. [in Russian].

9. Jiang, Y., Satoh, K., \& Watanabe, S. (2001). Inhibition of chlorogenic acid induced cytotoxicity by CoC12. Anticancer Res., 21, 3349-3353.

10. Herling, A.W., Burger, H.J., Schwab, D., Hemmerle, H., Below, P., \& Schubert, G. (1998). Pharmacodynamic profile of a novel inhibitor of the hepatic glucose-6-phosphatase system. Amer. J. Physiol., 274, 1087-1093.

11. Voitsekhivska, O.V., Sytar, O.V., \& Taran, N.Yu. (2015). Fenolni spoluky: riznomanittia, biolohichna aktyvnist, perspektyvy zastosuvannia [Phenolic compounds: diversity, biological activity, prospects of application]. Visnyk Kharkivskoho nats. Ahrarn. un-tu. Seriia biolohiia Journal of Kharkiv National Agriculture University. Series Biology, 1 (34), 104-119.

12. Ma, B., \& Liang, S. (2003). Progress report on extraction and separation ofchlorogenic acid from eucomiaulmoides. Shanxi For. Sci. Technol., 4, 74-79.

Э. А. Паращук, С. М. Марчишин, М. В. Кирилив, И. Р. Бекус ТЕРНОПОЛЬСКИЙ ГОСУДАРСТВЕННЫЙ МЕДИЦИНСКИЙ УНИВЕРСИТЕТ ИМЕНИ И. Я. ГОРБАЧЕВСКОГО

\section{СОДЕРЖАНИЕ КИСЛОТ ГИДРОКСИКОРИЧНЫХ В ТРАВЕ, КОРНЕВИЩАХ И КОРНЯХ БЕДРИНЦА КАМНЕЛОМКОВОГО (PIMPINELLA SAXIFRAGA L.)}

\section{Резюме}

Вступление. Бедринец камнеломковый (Pimpinella saxifraga L.) семейства сельдерейные (Apiaceae) издавна в народной медицине применяют как отхаркивающее, мочегонное, противовоспалительное, седативное, болеутоляющее средство. Его рекомендуют при катаре дыхательных путей, трахеите, бронхите, пневмонии, ларингите, астме, коклюше, водянке, солевых диатезах, заболеваниях печени, атонии кишечника, хроническом гастрите с пониженной кислотностью, подагре, отеках и метеоризме. С лечебной целью используют в основном корневища и корни растения. Известно около 200 видов рода Бедринец (Pimpinella L.), распространенных в Азии, Европе и Африке. В Украине встречаются 5 видов; наиболее распространенным является бедринец камнеломковый.

Цель исследования - установить наличие и определить количественное содержание кислот гидроксикоричных в траве и подземных органах бедринца камнеломкового.

Методы исследования. Для выявления кислот гидроксикоричных использовали спиртово-водную вытяжку. Реакция с 1 \% раствором фрерум (III) хлорида (появление зелено-серого цвета) свидетельствовала о наличии в исследуемой вытяжке соединений френольной природы. Количественное определение кислот гидроксикоричных в исследуемых объектах основывается на спектрофотометрическом методе. Качественный состав и количественное содержание индивидуальных кислот гидроксикоричных в траве и подземных органах бедринца камнеломкового исследовали методом высокоэфрфективной жидкостной хроматографрии на хроматографре Agilent 12003 D LC System Technologies (США).

Результаты и обсуждение. Количественное содержание суммы кислот гидроксикоричных в траве бедринца камнеломкового составляло $(4,68 \pm 0,05)$ \%, в подземных органах - $(1,52 \pm 0,03) \%$. Методом высокоэфррективной жидкостной хроматографии в исследуемых объектах растения выявлены и идентифицированы кислоты хлорогеновая и розмариновая и установлено их количественное содержание. В траве и подземных органах бедринца камнеломкового в основном доминирует кислота хлорогеновая, содержание которой составило 3,13 и 0,11 \% соответственно. В траве растения содержится 0,34 \% кислоты розмариновой.

Выводы. Установлено наличие и определено количественное содержание кислот гидроксикоричных в траве и подземных органах бедринца камнеломкового, которое составило $(4,68 \pm 0,05)$ и $(1,52 \pm 0,03) \%$ соответственно. Методом высокоэффрективной жидкостной хроматографии в исследуемом сырье растения выявлены индивидуальные кислоты гидроксикоричные - хлорогеновая и розмариновая, определено их количественное содержание. В траве и подземных органах бедринца камнеломкового доминирует кислота хлорогеновая, содержание которой составило 3,13 и 0,34 \% соответственно, поэтому ее можно рекомендовать для стандартизации сырья.

КЛЮЧЕВЫЕ СЛОВА: бедринец камнеломковый; кислоты гидроксикоричные; кислота хлорогеновая; спектрофотометрический метод; высокоэффективная жидкостная хроматография. 


\title{
CONTENT OF HYDROXYCINNAMIC ACIDS IN HERB AND RHIZOMES AND ROOTS OF SAXIFRAGE PIMPINELLA (PIMPINELLA SAXIFRAGA L.)
}

\begin{abstract}
Summary
Introduction. Saxifrage pimpinella (Pimpinella saxifraga L.) from the family of celery (Apiaceae) has long been used in folk medicine as expectorant, diuretic, anti-inflammatory, sedative, and pain medication. It is recommended for catarrhal airways, tracheitis, bronchitis, pneumonia, laryngitis, asthma, pertussis, edema, salt diathesis, liver disease, intestinal atony, chronic gastritis with low acidity, gout, swelling and flatulence. With therapeutic purposes, mainly, rhizomes and plant roots are used. There are about 200 species of the genus pimpinella (Pimpinella L.), common in Asia, Europe and Africa, there are 5 species in Ukraine; the most common is saxifrage pimpinella.

The aim of the study - to establish the presence and determine the quantitative content of hydroxycinnamic acids in the herb and subterraneous organs of the saxifrage pimpinella.

Research Methods. To detect hydroxycinnamic acids we used alcohol-water extractor. The reaction with $1 \%$ solution of ferrum (III) chloride (the appearance of green and gray color) indicated the presence of compounds of phenolic nature in the investigated extraction. The quantitative determination of hydroxycinnamic acids in the investigated objects is based on the spectrophotometric method. Qualitative composition and quantitative content of individual hydroxycinnamic acids in the herb and subterraneous organs of saxifrage pimpinella were investigated by high performance liquid chromatography (HPLC) on Agilent 12003 D LC System Technologies chromatograph (USA).

Results and Discussion. The quantitative content of the sum of hydroxycinnamic acids in the herb of the saxifrage pimpinella was $(4.68 \pm 0.05) \%$, in the subterraneous organs $-(1.52 \pm 0.03) \%$. The HPLC method in the investigated objects of the saxifrage pimpinella we revealed, identified and established the quantitative content of acids of chlorogenic and rosemary. Chlorogenic acid, the content of which was $3.13 \%$ and $0.11 \%$ respectively, is mainly the dominant in herb and subterraneous organs of the saxifrage pimpinella. Saxifrage pimpinella herb contains $0.34 \%$ of rosemary acid.

Conclusions. The presence and determination of the quantitative content of hydroxycinnamic acids in grass and subterraneous organs of the saxifrage pimpinella which was (4.68 \pm 0.05$) \%$ and $(1.52 \pm 0.03) \%$, respectively, was established. The method of HPLC analysis in the investigated raw material of the saxifrage pimpinella established individual hydroxycinnamic acids - chlorogenic and rosemary, and their quantitative content is determined. The dominant in the herb and subterraneous organs of the saxifrage pimpinella is chlorogenic acid, which content was $3.13 \%$ and $0.34 \%$, respectively, therefore it can be recommended for the standardization of raw materials.
\end{abstract}

KEY WORDS: saxifrage pimpinella; hydroxycinnamic acids; chlorogenic acid; spectrophotometric method; high performance liquid chromatography.

Отримано 30.07.18

Адреса для листування: С. М. Марчишин, Тернопільський державний медичний університет імені І. Я. Горбачевського, майдан Волі, 1, Тернопіль, 46001, Україна, e-mail: marchyshyn@tdmu.edu.ua. 